AFCRI $-63-671$

T. F. Webster

COMPUTATIONS OF THE EIDI HEAT

AND DENSITY TRANSPORTS

ACROSS THE GULF STREAM

BY

ABRAHAM H. OORT

MASSACHUSETTS INSTITUTE OF TECHNOLOGY

DEPARTMENT OF METEOROLOGY

CONTRACT NO. AF19 $(628)-2408$

PROJECT $8628 \quad$ TASK 862802

SCIENTIFIC REPORT NO. 1

PLANETARY CIRCULATIONS PROJECT

VICTOR P. STARR, DIRECTOR

1 JULY 1963

$G C$

167

68

07

1963

for

RCE CAMBRIDGE RESEARCH LABORATORIES

OF AEROSPACE RESEARCH

STATES AIR FORCE

D, MASSACHUSETTS 


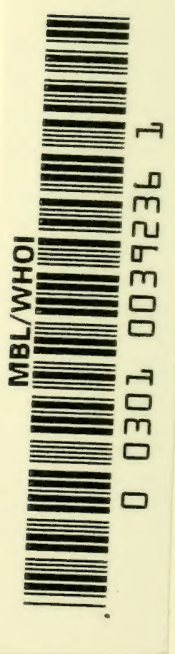


COMPUTATIONS OF THE EDDY HEAT AND DENSITY TRANSPORTS ACROSS THE GULF STREAM

BY

ABRAHAM H. OORT

MASSACHUSETTS INSTITUTE OF TECHNOLOGY DEPARTMENT OF METEOROLOGY

CONTRACT NO. AF19(628)-2408

PROJECT $8628 \quad$ TASK 862802

SCIENTIFIC REPORT NO. 1

PLANETARY GIRCULATIONS PROJECT VICTOR P. STARR, DIRECTOR

1 JULY 1963

Prepared for AIR FORCE CAMBRIDGE RESEARCH LABORATORIES OFFICE OF AEROSPACE RESEARCH UNITED STATES AIR FORCE BEDFORD, MASSACHUSETTS 
Requests for additional copies by Agencies of the Department of Defense, their contractors, and other Government agencies should be directed to the:

DEFENSE DOCUMENTATION CENTER (DDC) CAMERON STATION ALEXANDRIA, VIRGINIA

Department of Defense contractors must be established for DDC services or have their "need-to-know" certified by the cognizant military agency of their project or contract.

All other persons and organizations should apply to the:

U. S. DEPARTMENT OF COMMERCE OFFICE OF TECHNICAL SERVICES WASHINGTON 25, D. C. 
COMPUTATIONS OF THE EDDY HEAT AND DENSITY

TRANSPORTS ACROSS THE GULF STREAM

by

Abraham H. Oort

\begin{abstract}
Data of the current velocity, temperature and salinity
\end{abstract} of the Gulf Stream, collected during 200 crossings of the current in cruises off Onslow Bay, Jacksonville $\left(30^{\circ} \mathrm{N}\right)$ and Cape Hatteras, are used to compute the eddy fluxes of heat and density across the mean current. In each cruise an eddy transport of heat is observed, which is directed from the colder coastal water to the Sargasso Sea in the surface layers. The meanders in the stream appear to increase the thermal contrast across the so called Gulf Stream front and thus violate the ordinary diffusion laws by not transporting heat from the .warm to the cold source. The transport of density across the stream is, in general, towards the shore, reflecting mostly the influence of the temperature on the density.

Webster (1961b) has shown in an earlier study that there is a surface flow of kinetic energy and momentum from the meanders to the mean flow of the Gulf Stream. Since the meanders of the scale 
considered in these studies appear to speed up the Gulf Stream and do not feed upon, but actually build up the thermal contrast near the surface, these eddies must be forced.

More measurements of the kind described in this paper, are needed to verify the observed abnormal heat and density fluxes in the Gulf Stream.

Introduction

The remarkably intense system of currents observed on the western side of the North Atlantic Ocean forms a challenging problem for the dynamic oceanographer. The Gulf Stream System, as this set of currents is called, can be regarded as a boundary phenomenon associated with the sudden downward slope of the isotherms from the shore of the American continent towards the center of the ocean. The difference in density across the stream is probably not the driving force of the current but it forms one aspect of the equilibrium situation brought about by the effects of solar radiation, windstress, evaporation and rainfall at the surface of the ocean. It is often assumed that the typical meandering of the Gulf Stream dissipates part of the energy of the main flow. However, Webster (1961b) has shown that there is a surface flow of kinetic energy 
and momentum from the meanders to the main Gulf Stream, exactly opposite to what one would expect if the meanders were frictionally driven (see also Starr, 1961). There arises the problem of the source of energy for the meanders.

The present work forms an extension of Webster's study of the kinetic energy of the meanders to a consideration of the available potential energy in the Gulf Stream System. Current velocity, temperature and salinity measurements from three cruises along different sections of the stream are used to compute the eddy transports of heat and density across the Gulf Stream. The total number of crossings of the current exceeded 200.

\section{Data and their reduction}

Figure 1 shows the position of each cruise with respect to the coast line and the mean axis of the Gulf Stream (according to the U.S. Hydrographic Office). Except for the cruise south of Cape Hatteras the different crossings were made along the same line at right angles to the mean current and therefore overlapped each other.

(1) Cruise 18 of the research vessel "Crawford" by W.S. von Arx, D. F. Bumpus and C. G. Day during May 
and June 1958 was the source of information on the current near Onslow Bay. This cruise was set up to collect data on the behaviour of the meanders in a region where the Gulf Stream flows close to the shore over the Blake Plateau. The size of the meanders in this area is restricted by the continental shelf. One hundred and twenty crossings of the axis of the Gulf Stream off Onslow Bay were made for some thirty consecutive days. Every half hour the temperature was measured to a depth of $200 \mathrm{~m}$ with a bathythermograph; at the same time a sample of surface water was taken to be analyzed later for salinity. The current velocity was determined every hour by means of the geomagnetic electrokinetograph (GEK). Each crossing was continued across the current as far as was necessary to define the onshore edge of the band of maximumvelocity. A detailed description of the cruise and the measurements can be found in an article by T. F. Webster (1961a).

(2) In addition, data taken from cruise 70 of the "Crawford" by T. F. Webster during October and November 1961 were used in our computations. Some 70 crossings of the main axis of the stream were made along the $30^{\circ} \mathrm{N}$ parallel off Jacksonville where the stream runs essentially north-south; the technique of measuring temperature, salinity and current velocity was similar to the one described above. 


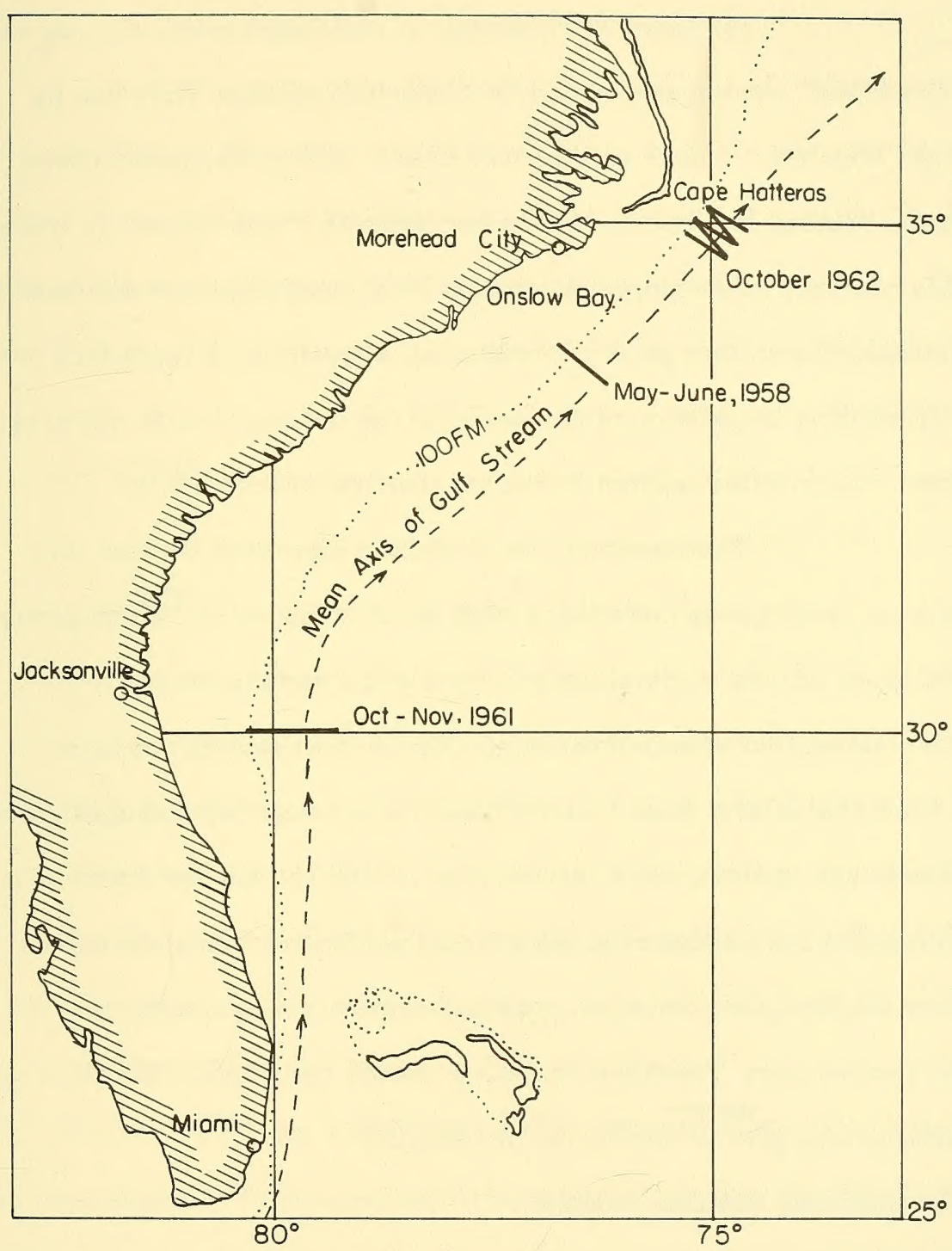

Fig. 1. Position of the cruises off Onslow Bay, off Jacksonville and off Cape Hatteras with respect to the coast line and the mean axis of the Gulf Stream (according to the U.S. Hydrographic Office). 
(3) Some 20 crossings of the Gulf Stream with the "Crawford" were made during October 1962 off Cape Hatteras by T.F. Webster. These data proved useful as an independent check of the results obtained in the earlier cruises. The crossings were in this case not made along the same line at right angles to the Gulf Stream, but shifted slowly downstream with time. Except for this shifting in position of the section, the measurements were taken in a similar fashion as during the first two cruises.

The observations of each cruise were divided into groups, each group covering a zone about $10 \mathrm{~km}$ wide. Each group contains the observations made at approximately the same distance from the mean axis of the Gulf Stream. The data in each group form a time series at a fixed location, and its average represents thus an average in time. For the first two cruises, only the zones with a number of observations exceeding 35 were used. In each zone the covariances in time of the cross current velocity $u$, the temperature $\mathrm{T}$ and the density $\rho$ were computed. These covariances give us the fluxes of interest. The following notation is used:

$u=v e l o c i t y$ of current normal to the time mean axis of the Gulf Stream (positive if in offshore direction) $\mathrm{v}=$ velocity of current in direction of mean 
axis (positive if downstream)

$$
\begin{aligned}
& \mathrm{T}=\text { temperature } \\
& \rho=\text { density } \\
& \sigma_{t}=(\rho-1) \times 1000, \text { where } \rho \text { in units of } \mathrm{g} \mathrm{cm}^{-3}
\end{aligned}
$$

Each of these quantities may be written as the sum of a time mean (indicated by bar) and a deviation of a time mean (indicated by prime). For example, for the cross stream velocity: $u=\tilde{u}+u$,

$$
\begin{aligned}
\overline{u^{\prime} T^{\prime}}= & \text { covariance in time of simultaneous cross } \\
& \text { current velocity and temperature } \\
\overline{u^{\prime} \rho^{\prime}}= & \text { covariance in time of simultaneous cross } \\
& \text { current velocity and density }
\end{aligned}
$$

The velocity components $\mathrm{u}$ and $\mathrm{v}$ were chosen in such a way that there is no net (in any case a very small) mass transport across the stream; i, e. $\overline{\mathrm{u}} \approx 0$. Nevertheless, it is possible to have a flux of "temperature" or density across the current due to the eddy exchanges of water masses of different temperature in a preferred direction. In our coordinate system:

$$
\overline{u T}=\bar{u}+\overline{u^{\prime} T^{\prime}} \approx \overline{u^{\prime} T^{\top}}
$$

The covariance $\overline{u^{\prime} T^{\prime}}$ represents, if multiplied with the density $\rho$ and the specific heat $c$, the eddy flux of heat across the current. In addition to the calculations at the surface, values of the heat 
transport off Onslow Bay and Jacksonville were computed at depths of $30 \mathrm{~m}, 60 \mathrm{~m}$ and $100 \mathrm{~m}$. It seemed reasonable to use in these calculations the surface velocity measured by the GEK as representative of the current down to a depth of $100 \mathrm{~m}$. At any rate velocities were available for the surface only. For the cruise south of Cape Hatteras surface data only were used in all computations.

Discussion of the observed heat and density transport

Upon examination of a temperature cross section of the Gulf Stream one notices a strong horizontal temperature contrast between the slope water and the Sargasso Sea in the vicinity of the current maximum (see e.g. fig. 2). One is immediately tempted to ask the following questions: Is there a transport of heat across the current produced by the meanders and, if present, is this flux down the gradient and what is its magnitude?

The calculated values of the eddy fluxes of heat and density are presented in tables 1,2 and 3 . Assuming that the present data are representative for the layers of the Gulf Stream near the surface, the observations suggest an unexpected answer to our questions. In all three sections there is apparent a 

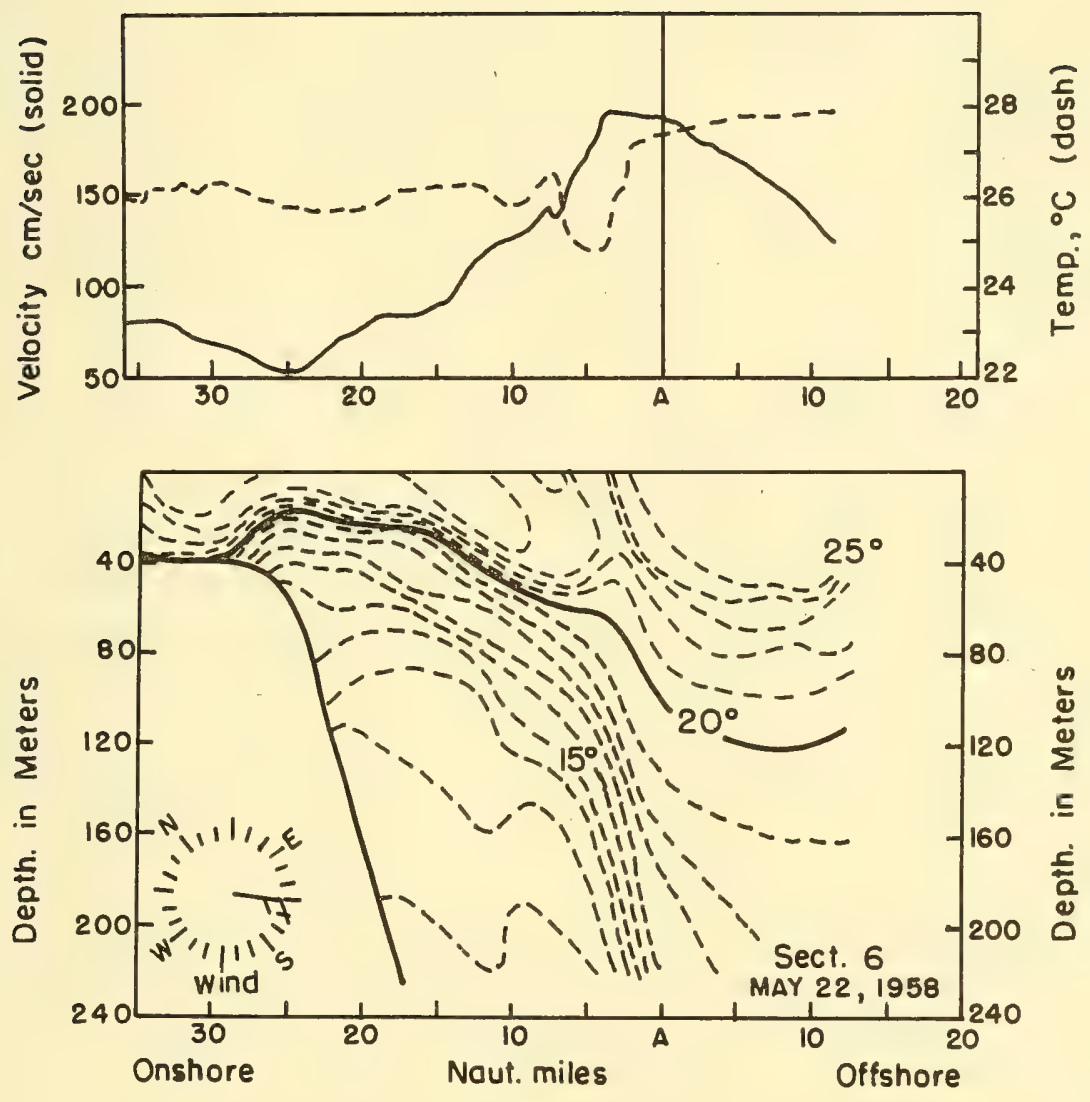

Fig. 2. A typical distribution of temperature and current velocity for a single crossing of the Gulf Stream off Onslow Bay. The mean axis of the Gulf Stream is indicated by the letter A. (after Webster 1961a). 
countergradient eddy flux of heat, i. e., a flux of heat from the colder coastal waters to the warmer ocean. The observed heat and density fluxes are shown in figures 3,4 and 5 . It is remarkable how strong the observed heat transport is in the Onslow Bay and Cape Hatteras sections with, at the surface, a maximum of the order of $+10^{\circ} \mathrm{C} \mathrm{cm} \mathrm{sec}^{-1}$, located near the maximum of the current. The transport decreases with distance from the axis of the current. In the Jacksonville surface data the mean temperature profile is flat and the corresponding heat flux small. Yet a small peak shows up similar to the maxima in the other sections, indicating again a transport against the gradient. With increasing depth below the surface the temperature gradient becomes steeper and the peak of the eddy heat flux sharper. Even at Jacksonville, where the heat flux at the surface is ill defined, there is a strong heat transport below the surface. In tables 1, 2 and 3 are also presented density fluxes, computed from the available data for temperature and salinity at the surface. In most cases the density transport is towards the shore. However, the action is not quite so systematic as for the transport of heat, except at Onslow Bay. 
In the last line of the tables the data for the different zones of each cruise are added together. This corresponds to an additional averaging in space along a line at right angles to the current over a distance of about $80 \mathrm{~km}$. A mean eddy heat flux with a range from 1 to $4^{\circ} \mathrm{C} \mathrm{cm} \mathrm{sec}^{-1}$ and a mean eddy density flux of -0.2 to $-1.8 \times 10^{-3} \mathrm{gm} \mathrm{sec}^{-1} \mathrm{~cm}^{-2}$ is found.

The reliability of the measured covariances is estimated by use of the standard error of the mean, computed as the standard deviation divided by the square root of the number of observations, e.g., S. E. $\left(\overline{u^{\prime} T^{\prime}}\right)=\sqrt{\left(u^{\prime} T^{\prime}\right)^{2}}-\left(\overline{u^{\prime} T^{\prime}}\right)^{2} / \sqrt{N}$. Twice the standard error of the mean gives the value of the $95 \%$ confidence limit. It is assumed that the observations are independent, which is not exactly true since the observations in each zone are taken in the most favorable case 12 hours apart. There will be some correlation in time between the different observations, which will tend to give too small standard errors of the mean. In the average of all data for a cruise, there will be a correlation of the observations in space as well as in time. However, the close resemblance of the results of three independent cruises, which were made in different years and different parts of the Gulf Stream, supports the suggestion of an existing positive transport of heat and negative transport of density in the layers 
Ф)

+1 先造

$\sim$ 宁 0 调

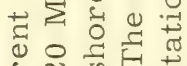

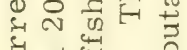

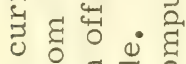

Е

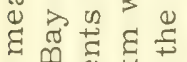

(1) 1 U 4

我 30.

ज

प) है के है

\& 0 का

ठี

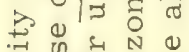

पू ज :

(1) है $E$ ह

D

สี फ

ข 400

ङ

के है $>$ के है

¿1 0100

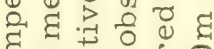

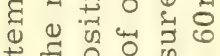

$+\mp 0$ O 0

फ

प द्न है हृ

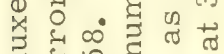

㗚

ते

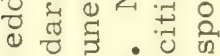

Е

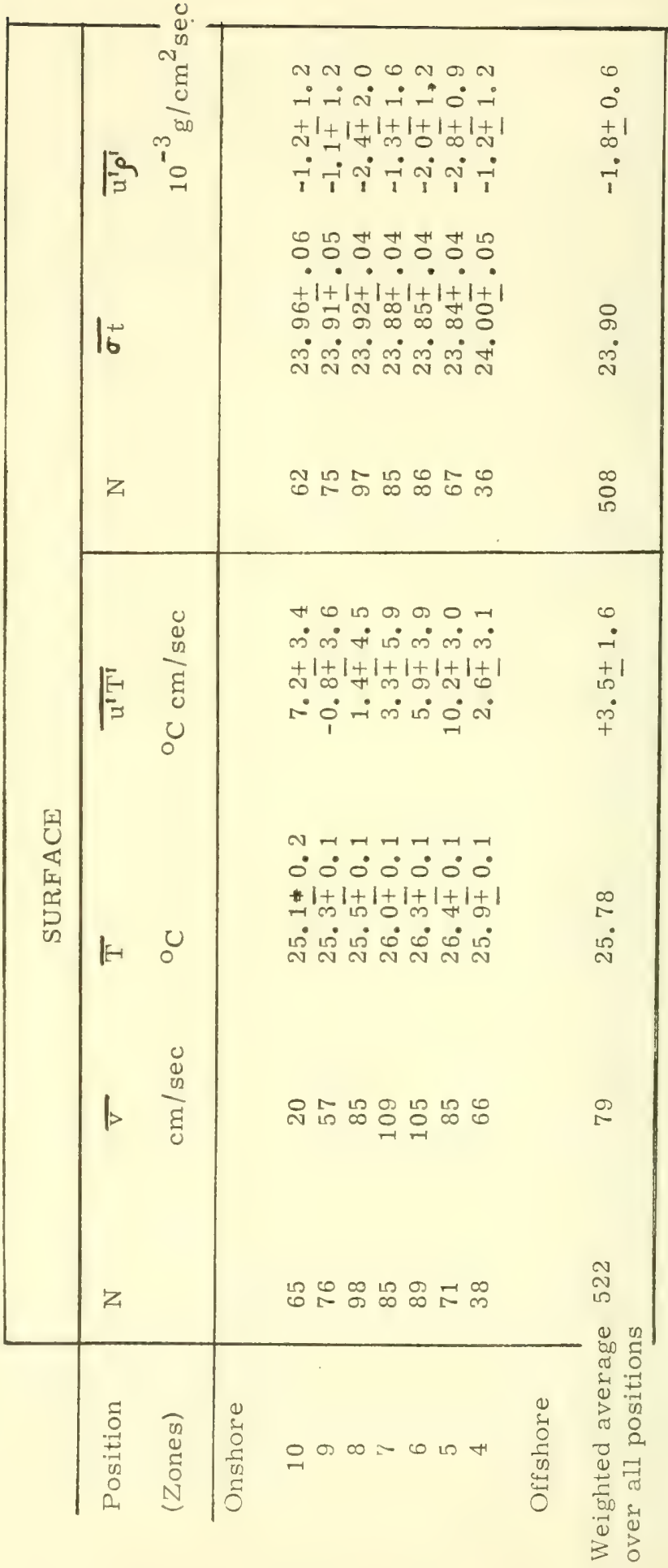




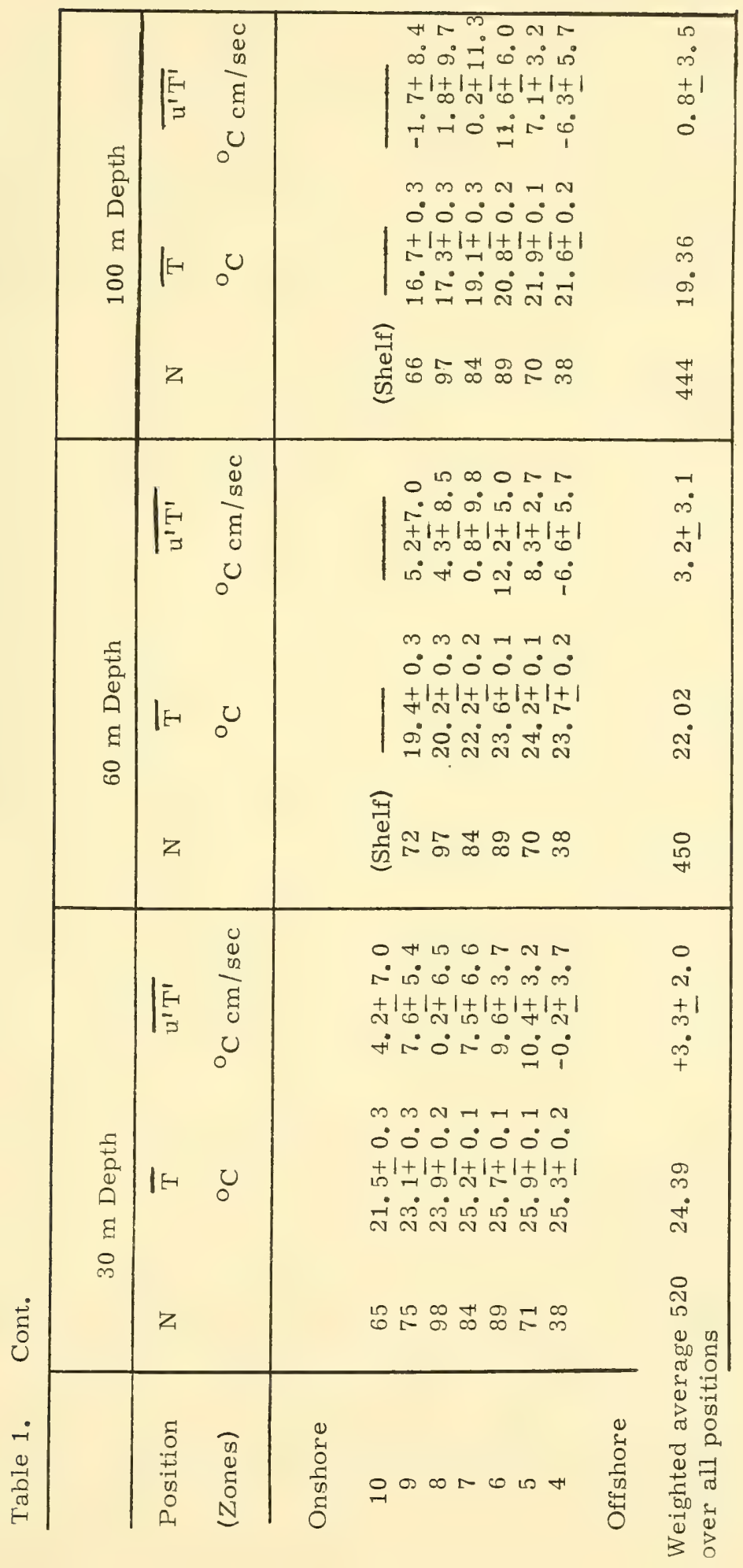




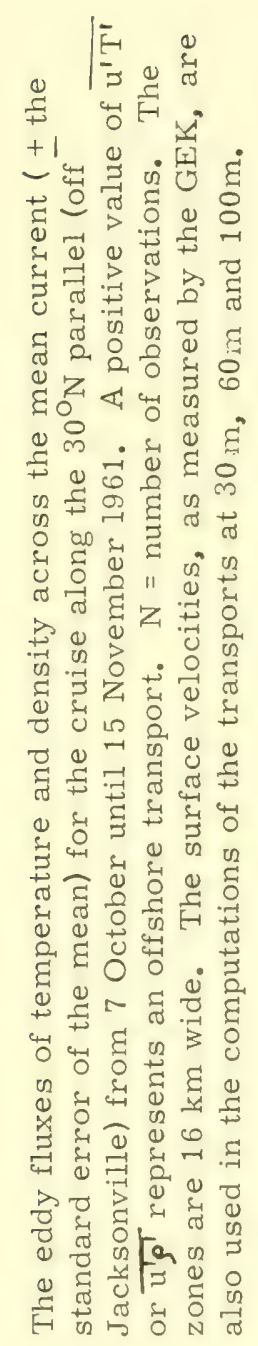

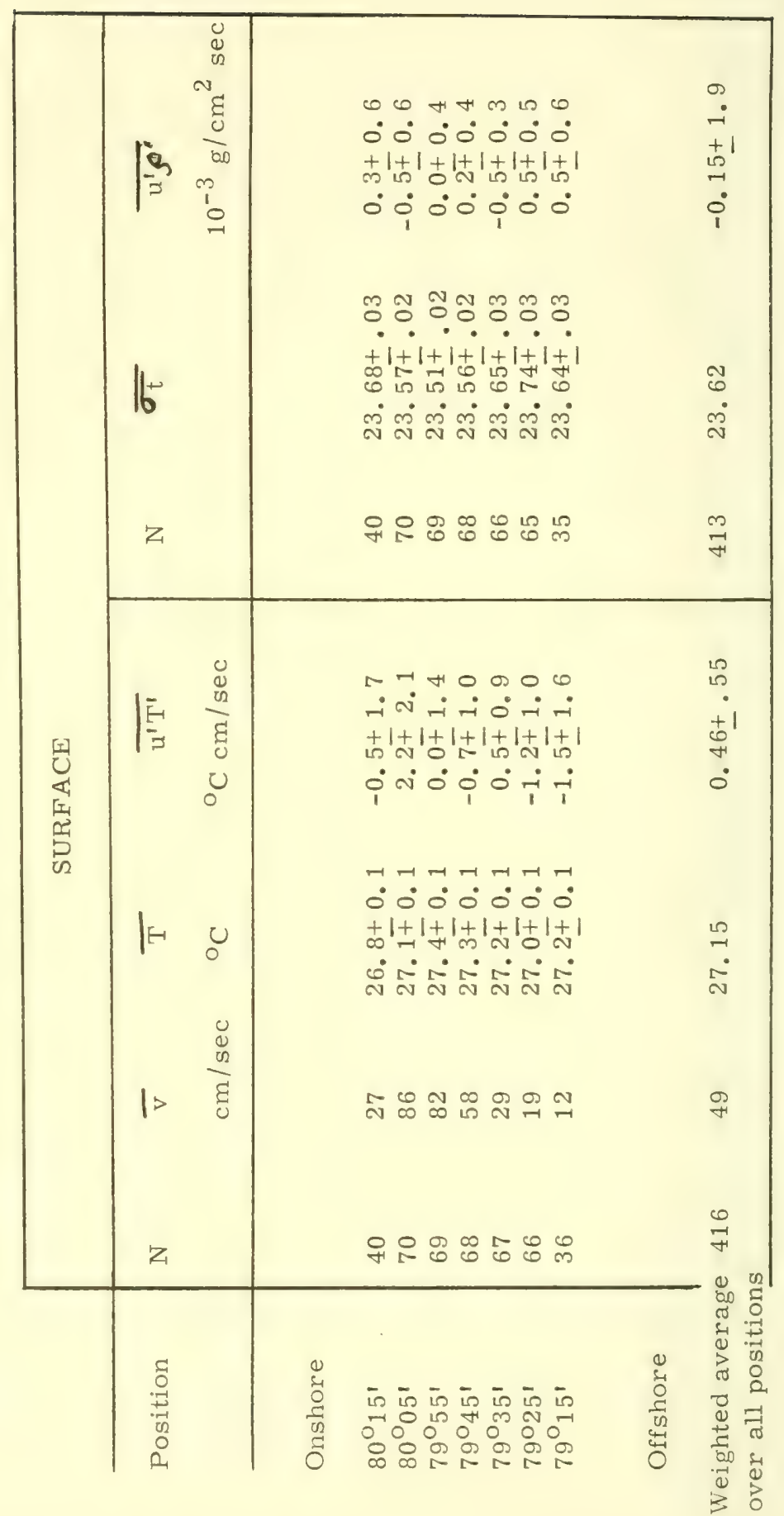




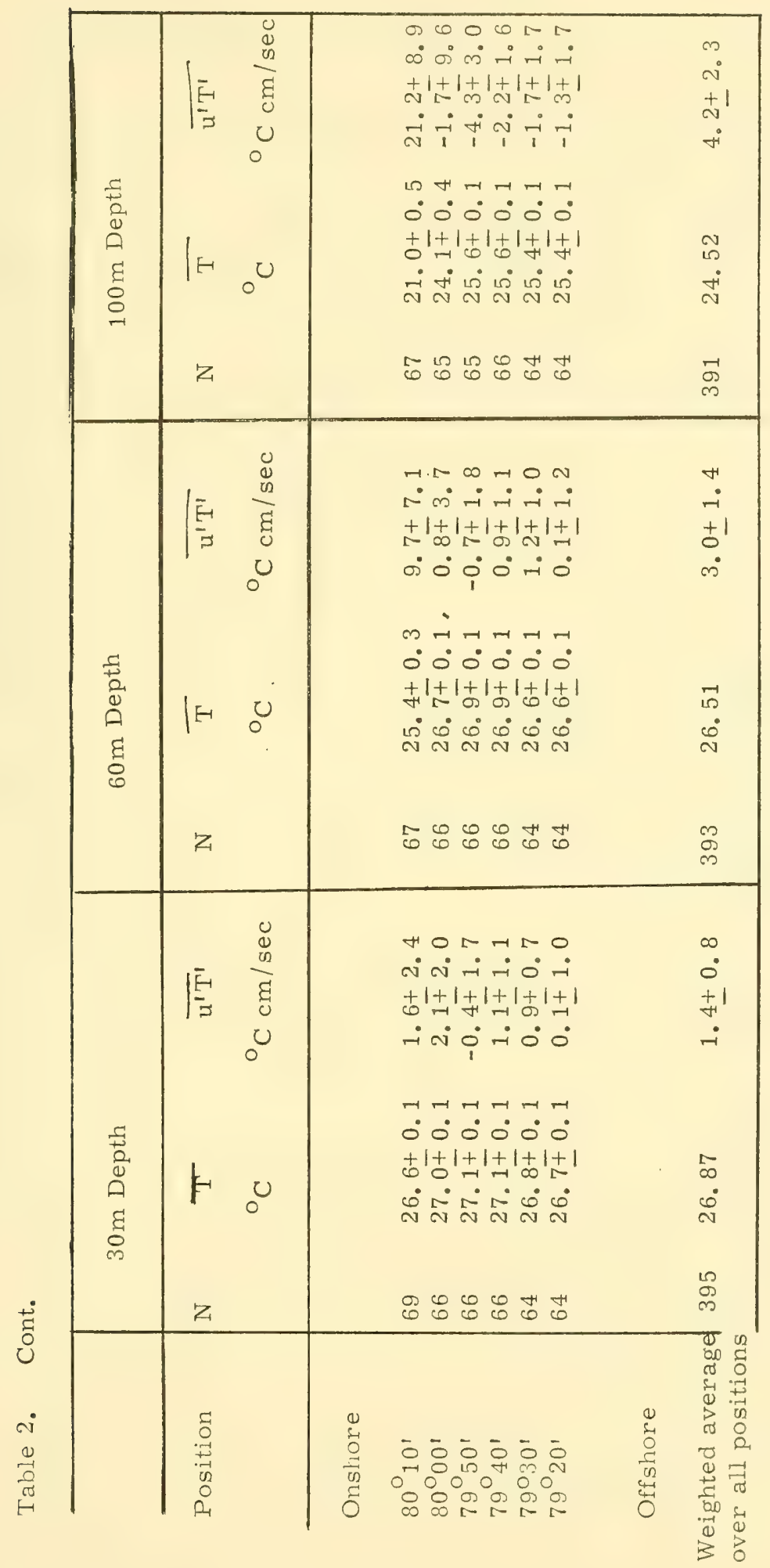




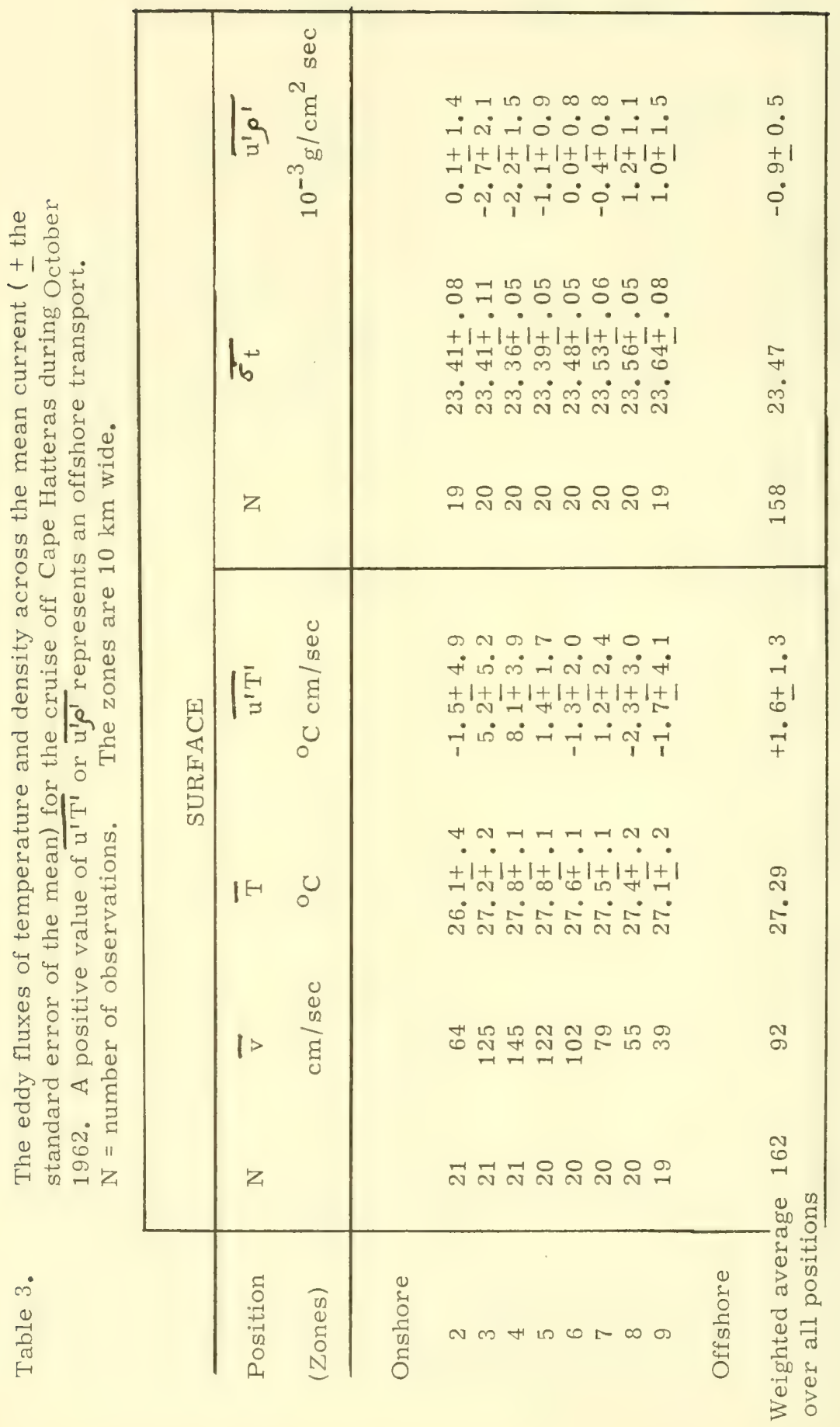


near the surface.

The maximum in the offshore heat flux coincides approximately with the place of maximum current velocity. This could explain the broadening of the temperature maximum (warm core) to the right of the current peak (facing downstream) which is apparent in our data. Stommel (1960) defines the warm core as that part of the Gulf Stream containing water warmer than the water at the same depth to the right of the current. The core is according to Stommel generally $300 \mathrm{~m}$ to $400 \mathrm{~m}$ deep; with the maximumtemperature anomalies at a depth of about $100 \mathrm{~m}$. In order to get an idea of the order of magnitude of possible effects of the computed fluxes, one can calculate the heat transport normal to a vertical strip following the direction of the Gulf Stream along its axis for a distance of $1000 \mathrm{~km}$ and with a depth of $100 \mathrm{~m}$. Let us assume a covariance of $\overline{u^{1} T^{1}}=+10^{\circ} \mathrm{C} \mathrm{cm} \mathrm{sec}^{-1}$. The heat transport $\rho c \overline{u^{\prime} T^{\prime}}$ across the strip turns out to be of the order of $10^{18} \mathrm{cal} \mathrm{day}^{-1}$. This amount is not insignificant if compared with the calculated annual poleward transport of heat of $20 \times 10^{18} \mathrm{cal} \mathrm{day}^{-1}$ at $30^{\circ} \mathrm{N}$ by the entire North Atlantic Ocean (see Von Arx, 1962, p, 149). At this latitude the North Atlantic is about $6700 \mathrm{~km}$ wide. 
Computation of the conversion of available potential energy

Lorenz (1955) derived expressions for the generation and conversion of zonal and eddy available potential energy in the atmosphere. In the case of our data for the Gulf Stream, it is only possible to compute the contribution of one of the many analogous terms in the balance of available potential energy. This term

$$
C_{A}=\varepsilon g \iint \Gamma^{-1} \overline{u^{\prime} T^{\prime}} \frac{\partial \bar{T}}{\partial x} \rho_{0} d x d z
$$

may be called the conversion by horizontal processes of available potential energy of the meanders to available potential energy of the mean flow. We suppose here that the available potential energy is due entirely to the temperature distribution. Also $\widetilde{r}$ = average over all data of one cruise at a certain depth (i. e, average in time and over $\mathrm{x}$ - coordinate)

$\Gamma=\partial \widetilde{T} / \partial z$ and replaces the difference between the dry adiabatic and actual lapse rate in the atmospheric case.

$$
\begin{aligned}
\rho= & \rho_{0}(1-\Sigma T), \text { where } \varepsilon=3 \times 10^{-4} \mathrm{deg}^{-1} \\
x= & \text { space coordinate along line at right } \\
& \text { angles to the mean current (positive } \\
& \text { if towards ocean) }
\end{aligned}
$$


Table 4. Conversion of available potential energy of the meanders to available potential energy of the mean flow. Units are in $10^{-3}$ ergs $\mathrm{cm}^{-3} \mathrm{sec}^{-1}$.

Onslow Bay

\begin{tabular}{|c|c|c|c|}
\hline Surface & $30 \mathrm{~m}$ & $60 \mathrm{~m}$ & $100 \mathrm{~m}$ \\
\hline 0.3 & 1.6 & 1.9 & 2.0 \\
0.2 & 0.2 & 0.8 & 1.9 \\
0.6 & $\ldots \ldots$ & $\ldots-$ & $\ldots$ \\
\hline
\end{tabular}

Cape Hatteras 
$\mathrm{z} \quad=$ vertical space coordinate (positive

if upwards)

Since our data show a heat transport in the direction of the warmer ocean, a positive value of $\mathrm{C}_{\mathrm{A}}$ is to be expected. The values of $\mathrm{C}_{\mathrm{A}}$ for the different sections and depths are presented in table 4. All values are positive signifying a build up of mean available potential energy at the expense of the eddy available potential energy.

The value of the conversion of eddy available potential energy to that of the mean flow at the surface off Onslow Bay is $3 \times 10^{-4} \mathrm{erg} \mathrm{cm}^{-3} \mathrm{sec}^{-1}$. Webster (1961b) computes for this section a transfer of kinetic energy from the eddies to the mean flow of $80 \times 10^{-4} \mathrm{erg} \mathrm{cm}^{-3} \mathrm{sec}^{-1}$ at the surface.

\section{Concluding Remarks}

This study gives an indication of an inverse eddy diffusion process taking place; water parcels which move offshore are relatively warm (low density) and parcels moving onshore are relatively cold (high density). It could be that water particles traveling towards the open ocean have their origin in general at higher (warmer) levels in the ocean and /or vice versa. 
These parcels are consequently warmer than the surrounding water and in a position to transport heat across the mean flow in the direction of the ocean. This would be equivalent to the existence of a negative correlation between the vertical motion and the instantaneous cross stream velocity. Such a possible mechanism throws, however, no light on the question of the cause of the countergradient heat flux. Since the meanders draw their energy neither from the kinetic energy of the main stream (Webster 1961b), nor according to this study from the available potential energy of the mean current, these eddies must have an outside source of energy. The following possibilities seem to be left: (1) the meanders at or near the surface are forced by the ocean circulation at greater depths (2) the meanders are forced by the tropospheric circulations (3) the meanders receive energy by advection or pressure work at the vertical boundaries. It might be thought that the expression for $\mathrm{C}_{\mathrm{A}}$ is inadequate in that it involves only the temperature effects and not those due to the salinity. A more accurate substitute incorporating salinity would formally 
represent a complete thermohaline process. However, the prospect of securing a source of energy for the eddies through this means appears not to be encouraging in view of the density transports calculated from temperature and salinity data for the surface, especially in the case of what appears to be the best observations namely those at Onslow Bay.

As an illustration of a probably forced regime in the atmosphere, it is interesting to consider the lower stratosphere. In the troposphere the transport of heat is down the gradient (poleward) as in a nornal heat engine, but in the lower stratosphere a reversal of the temperature gradient takes place, while the horizontal eddies still transport the heat poleward as in the troposphere (White, 1954). In the atmospheric case it is possibly justified to say that the regime in the lower stratosphere is partly forced by the underlying tropospheric circulation. The results of Webster's study (1961b) and the present one indicate that the meanders play an important role in the maintenance of the Gulf Stream and that the question of the distribution of stream velocity or temperature cannot be separated from that of the existence and action of the meanders. It is necessary to obtain more observations from different sections of the Gulf Stream in order to be able to verify the described abnormal heat transport. It would be extremely 
interesting to extend the heat and density flux measurements to lower levels in the ocean.

\section{Acknowledgement}

The author is very grateful to Dr. T. F. Webster for making available the partly unpublished data used in this study and for various advice in handling this material. Also Prof. Victor P. Starr is to be credited for encouragement and valuable discussions. Thanks are due to Miss Isabel Kole for drafting the figures. Finally, the author is indebted to the "Netherlands Organization for Advancement of Pure Research (Z. W. O. )" for financial support in the form of a Nato Science Fellowship. 


\section{References}

Lorenz, E. N., 1955: Available potential energy and the maintenance of the general circulation. Tellus 7, 157-167. Starr, V. P., 1961: Hydrodynamical red-shift phenomena in geophysics. Geofisica Pura e Applicata, 48, 109-123.

Stommel, H., 1960: "The Gulf Stream; a physical and dynamical description". Berkeley, USA; University of California Press, 202 pp.

Von Arx, W. S., 1962: "Introduction to Physical Oceanography", Reading, Mass. USA. Addison-Wesley Publishing Company, Inc., 422 pp.

Webster, T.F., 1961a: A description of Gulf Stream meanders off Onslow Bay. Deep-Sea Research 8, 130-143.

Webster, T. F., 1961b: The effects of meanders on the kinetic energy balance of the Gulf Stream. Tellus 13, $392-401$.

White, R. M., 1954: The counter-gradient flux of sensible heat in the lower stratosphere. Tellus 6, 177-179. 
$-25-$ 

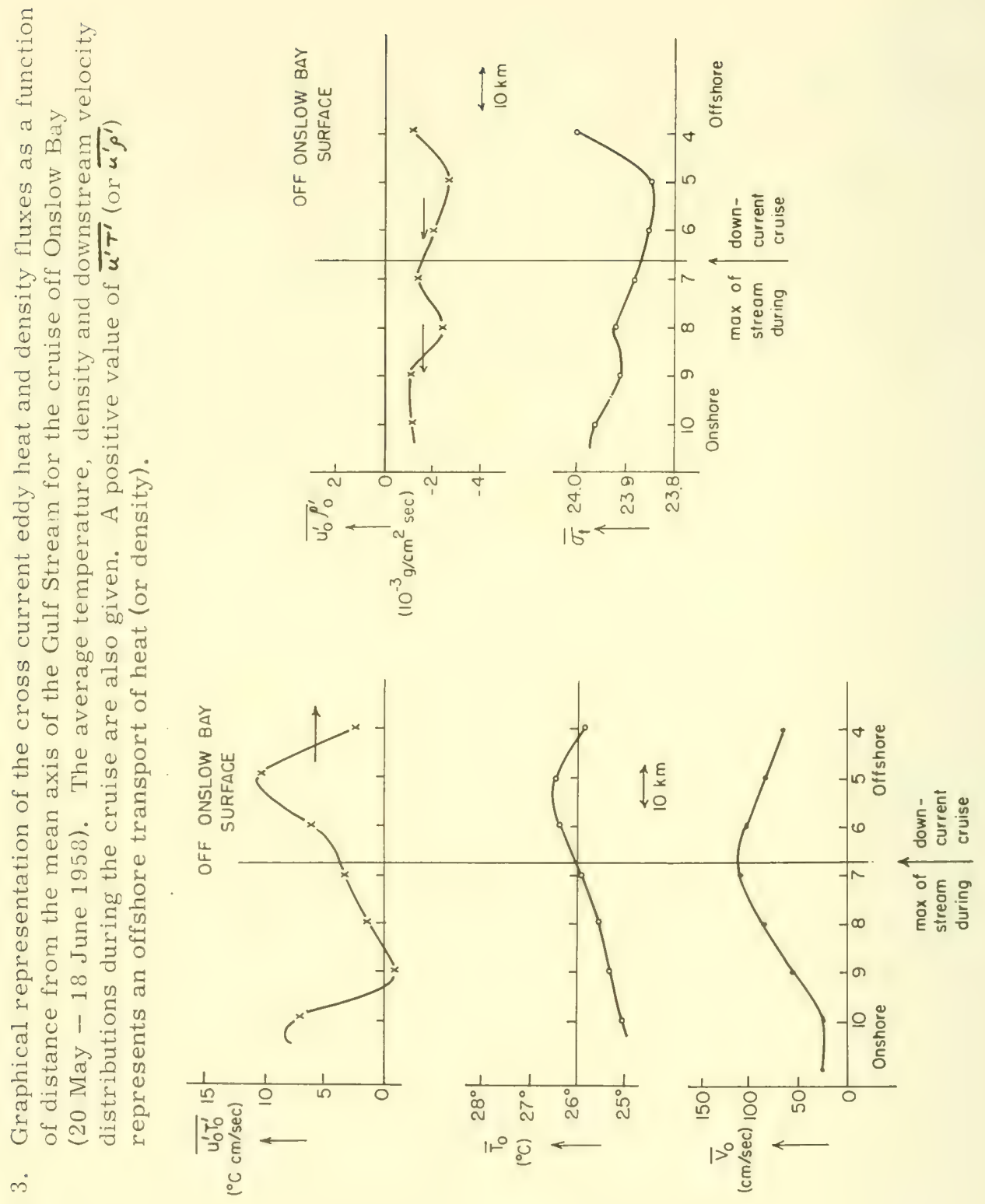


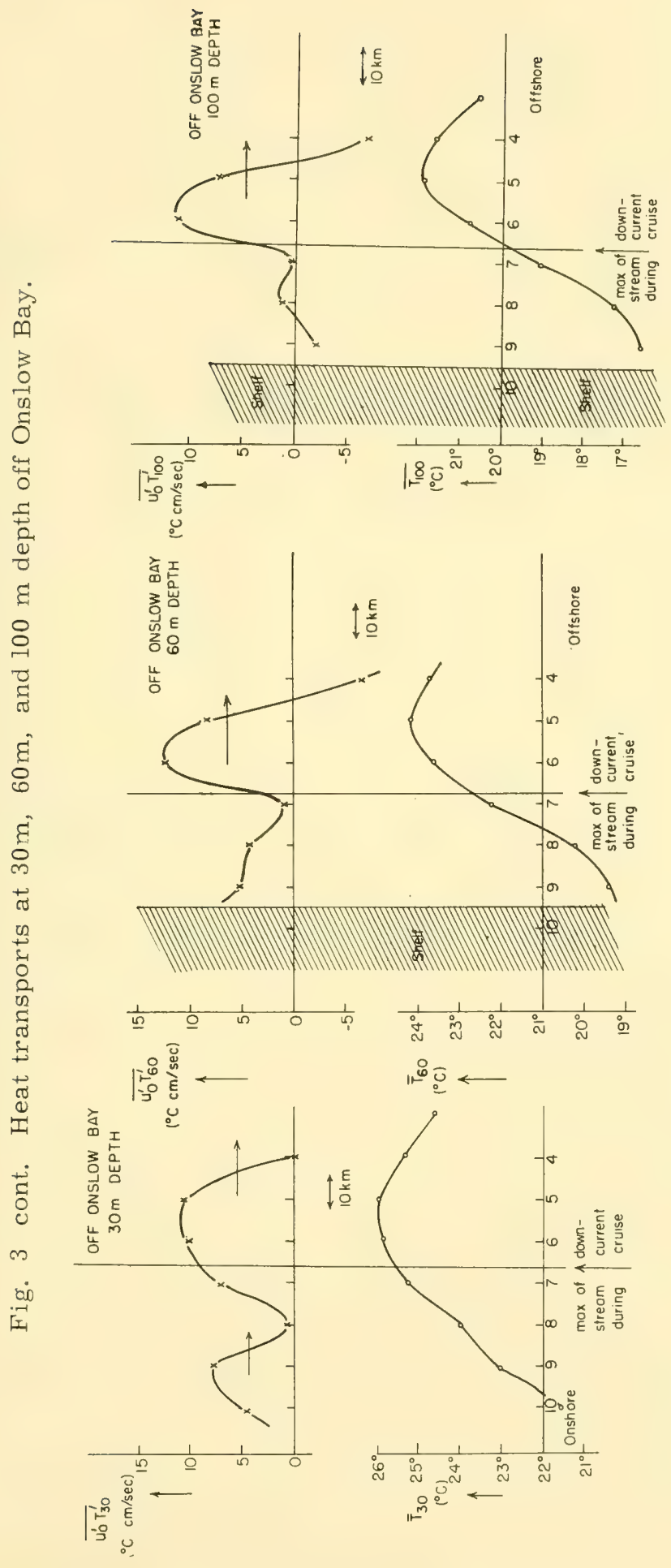




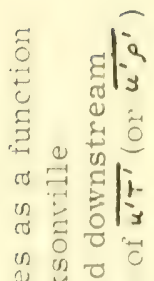

兵岳

ले

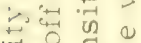

in 4 :

Q i n

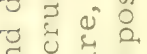

ब 31

$\leftarrow \leftleftarrows$

(1)

E.

उद्

ए तो क 0 है

$+\stackrel{0}{2}$ क क

का है क्ष

\& $4 \geqslant 0$

उै

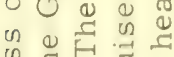

0 ॠ $Е$ है

பै山 $\ddot{0} \dot{0} 0$

य) थ

\# त्व $\rightarrow$ bo

- \& \& छ

द ते है

¿ E E 0

(⿻)

$\rightleftarrows \frac{0}{0} \frac{1}{0}$

(1) छ以

i 0 - 00

क्ष । स टा

40,0 on

तु 0 \&

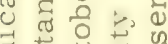

की त 虫出 0

$+$

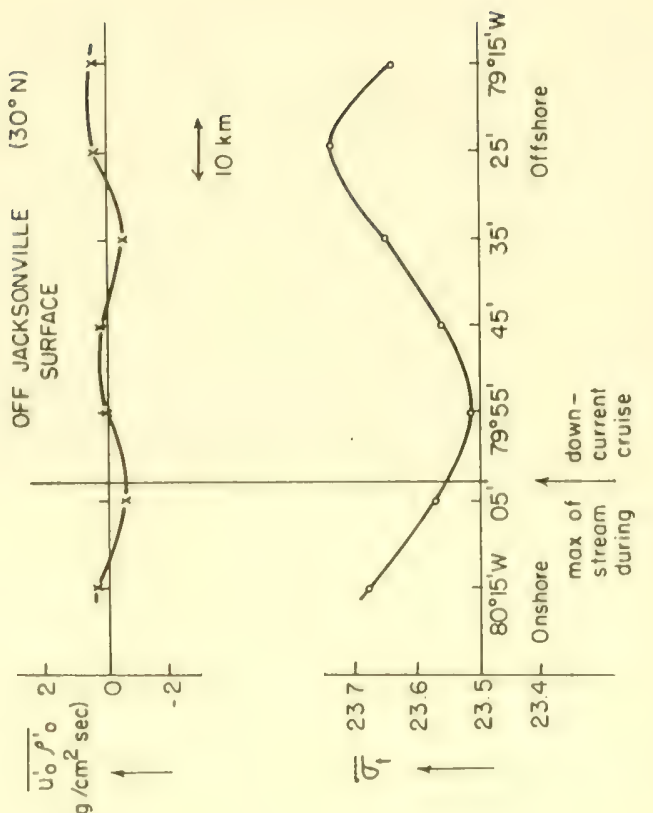

2
0
0
0

苍品

व

荘

?

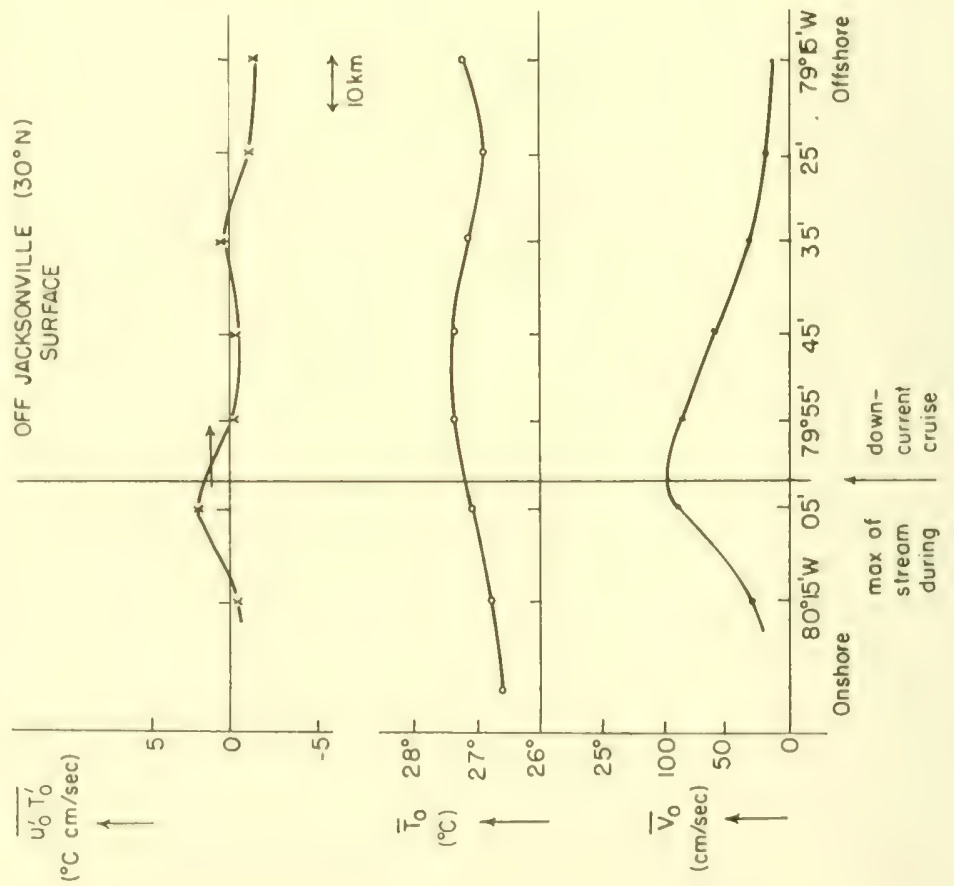




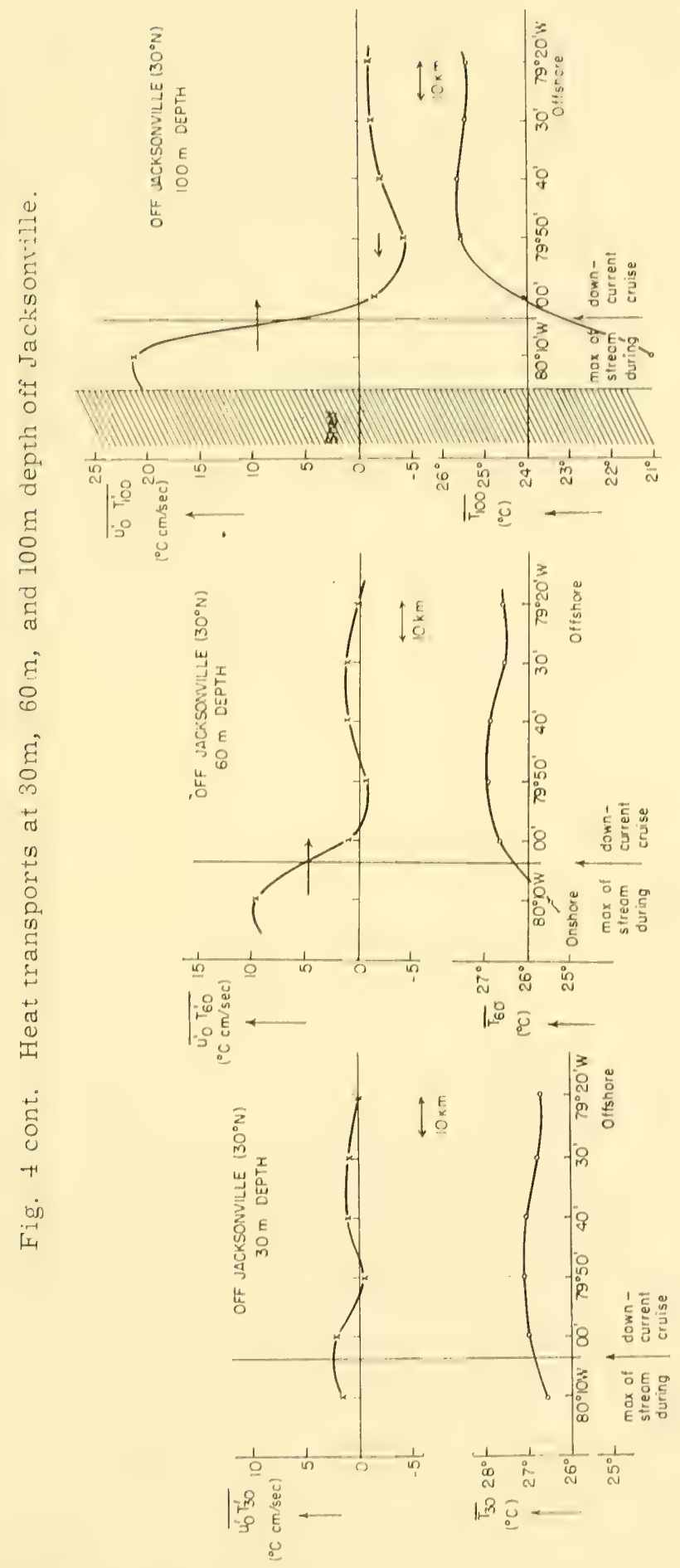




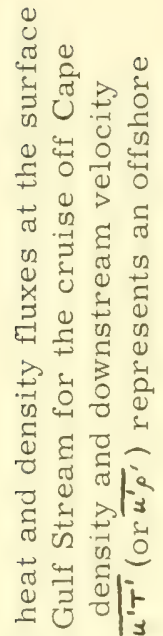

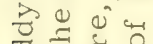

४⿻

¿ 0 ॠ

4 त 0 , $>$

उन छे छ

ปี

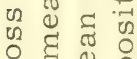

0 ह छ

प्र ट्व

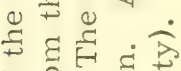

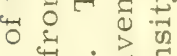

द्व 2 के की

$\rightarrow$ U 00 o

๘ $\underset{\pi}{\pi}$ क

प)

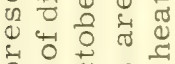

\&

न पे थ

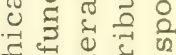

है

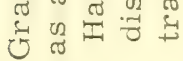

15

$=0$
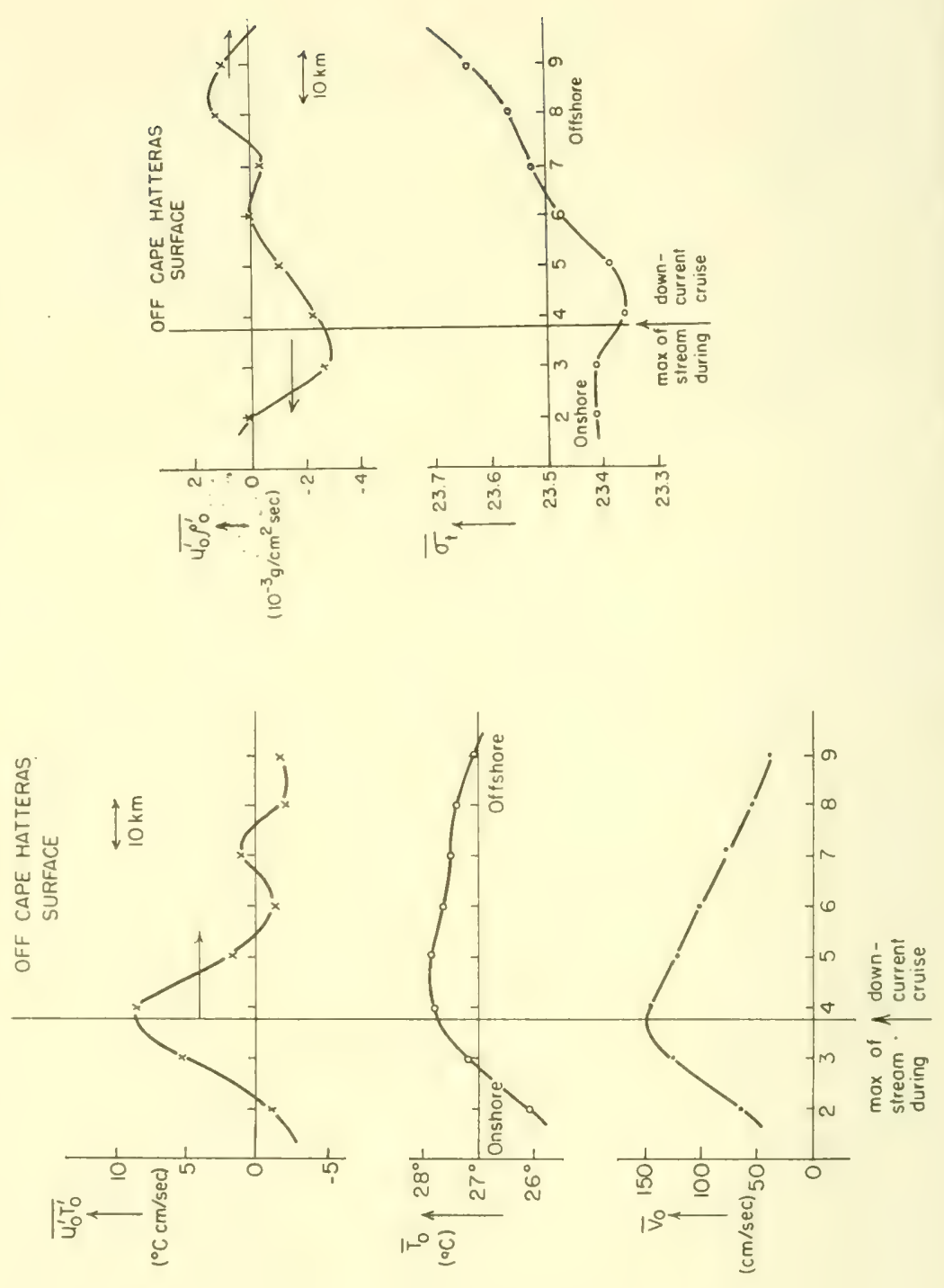
Planetary Circulations Project, Massachusetts Institute of Technology Cambridge, Massachusetts

Report No. AFCRL - 63

\section{COMPUTATIONS OF THE EDDY HEAT AND DENSITY} TRANSPORTS ACROSS THE GULF STREAM

by

Abraham H. Oort
Unclassified

1. Gulf Stream

2. Heat and density transport

3. Abraham H. Oort

Scientific Report No. 1, 1 July 1963, 30 pages, AF19 (628)-2408

Unclassified Report.

Data of the current velocity, temperature and salinity of the Gulf Stream, collected during 200 crossings of the current in cruises off Onslow Bay, Jacksonville $\left(30^{\circ} \mathrm{N}\right)$ and Cape Hatteras, are used to compute the eddy fluxes of heat and density across the mean current. In each cruise an eddy transport of heat is observed, which is directed from the colder coastal water to the Sargasso Sea in the surface layers. The meanders in the stream appear to increase the thermal contrast across the so called Gulf Stream front and thus violate the ordinary diffusion laws by not transporting heat from the warm to the cold source. The transport of density across the stream is, in general, towards the shore, reflecting mostly the influence of the temperature on the density. Since the meanders of the scale considered in this study appear to speed up the Gulf Stream and do not feed upon, but actually build up the thermal contrast near the surface, these eddies must be forced.

Planetary Circulations Project, Massachusetts Institute of Technology Cambridge, Massachusetts

Report No. AFCRL - 63

\section{COMPUTATIONS OF THE EDDY HEAT AND DENSITY TRANSPORTS ACROSS THE GULF STREAM}

by

Abraham H, Oort

Scientific Report No, 1, I July 1963, 30 pages, AF19 (628)-2408 Unclassified Report.

Data of the current velocity, temperature and salinity of the Gulf Stream, collected during 200 crossings of the current in cruises off Onslow Bay, Jacksonville $\left(30^{\circ} \mathrm{N}\right)$ and Cape Hatteras, are used to compute the eddy fluxes of heat and density across the mean current. In each cruise an eddy transport of heat is observed, which is directed from the colder coastal water to the Sargasso Sea in the surface layers. The meanders in the stream appear to increase the thermal contrast across the so called Gulf Stream front and thus violate the ordinary diffusion laws by not transporting heat from the warm to the cold source. The transport of density across the stream is, in general, towards the shore, reflecting mostly the influence of the temperature on the density. Since the meanders of the scale considered in this study appear to speed up the Gulf Stream and do not feed upon, but actually build up the thermal contrast near the surface, these eddies must be forced.

1. Gulf Stream

2. Heat and density transport

3. Abraham H. Oort 

Planetary Circulations Project, Massachusetts Institute of Technology Cambridge, Massachusetts

Report No. AFCRL - 63

\section{COMPUTATIONS OF THE EDDY HEAT AND DENSITY TRANSPORTS ACROSS THE GULF STREAM}

by

Abraham H. Oort
1. Gulf Stream

2. Heat and density transport

3. Abraham H. Oort

Scientific Report No. 1, 1 July 1963, 30 pages, AF19 (628)-2408

Unclassified Report.

Data of the current velocity, temperature and salinity of the Gulf Stream, collected during 200 crossings of the current in cruises off Onslow Bay, Jacksonville $\left(30^{\circ} \mathrm{N}\right)$ and Cape Hatteras, are used to compute the eddy fluxes of heat and density across the mean current. In each cruise an eddy transport of heat is observed, which is directed from the colder coastal water to the Sargasso Sea in the surface layers. The meanders in the stream appear to increase the thermal contrast across the so called Gulf Stream front and thus violate the ordinary diffusion laws by not transporting heat from the warm to the cold source. The transport of density across the stream is, in general, towards the shore,

reflecting mostly the influence of the temperature on the density. Since the meanders of the scale considered in this study appear to speed up the Gulf Stream and do not feed upon, but actually build up the thermal contrast near the surface, these eddies must be forced.

Planetary Circulations Project, Massachusetts Institute of Technology Cambridge, Massachusetts

Report No. AFCRL - 63

\section{COMPUTATIONS OF THE EDDY HEAT AND DENSITY TRANSPORTS ACROSS THE GULF STREAM}

by

Abraham H. Oort

Scientific Report No, 1, 1 July 1963, 30 pages, AF19 (628)-2408 Unclassified Report.

Data of the current velocity, temperature and salinity of the Gulf Stream, collected during 200 crossings of the current in cruises off Onslow Bay, Jacksonville $\left(30^{\circ} \mathrm{N}\right)$ and Cape Hatteras, are used to compute the eddy fluxes of heat and density across the mean current. In each cruise an eddy transport of heat is observed, which is directed from the colder coastal water to the Sargasso Sea in the surface layers. The meanders in the stream appear to increase the thermal contrast across the so called Gulf Stream front and thus violate the ordinary diffusion laws by not transporting heat from the warm to the cold source. The transport of density across the stream is, in general, towards the shore,

reflecting mostly the influence of the temperature on the density. Since the meanders of the scale considered in this study appear to speed up the Gulf Stream and do not feed upon, but actually build up the thermal contrast near the surface, these eddies must be forced.
Unclassified

1. Gulf Stream

2. Heat and density transport

3. Abraham H, Oort 

Planetary Circulations Project, Massachusetts Institute of Technology Cambridge, Massachusetts

Report No. AFCRL - 63

\section{COMPUTATIONS OF THE EDDY HEAT AND DENSITY} TRANSPORTS ACROSS THE GULF STREAM

by

Abraham H. Oart
Unclassified

1. Gulf Stream

2. Heat and density transport

3. Abraham $\mathrm{H}$, Oort

Scientific Report No. 1, 1 July 1963, 30 pages, AF19 (628)-2408

Unclassified Report.

Data of the current velocity, temperature and salinity of the Gulf Stream, collected during 200 crossings of the current in cruises off Onslow Bay, Jacksonville $\left(30^{\circ} \mathrm{N}\right)$ and Cape Hatteras, are used to compute the eddy fluxes of heat and density across the mean current. In each cruise an eddy transport of heat is observed, which is directed from the colder coastal water to the Sargasso Sea in the surface layers. The meanders in the stream appear to increase the thermal contrast across the so called Gulf Stream front and thus violate the ordinary diffusion laws by not transporting heat from the warm to the cold source. The transport of density across the stream is, in general, towards the shore, reflecting mostly the influence of the temperature on the density. Since the meanders of the scale considered in this study appear to speed up the Gulf Stream and do not feed upon, but actually build up the thermal contrast near the surface, these eddies must be forced.

Planetary Circulations Project, Massachusetts Institute of Technology Cambridge, Massachusetts

Report No, AFCRL - 63

\section{COMPUTATIONS OF THE EDDY HEAT AND DENSITY TRANSPORTS ACROSS THE GULF STREAM}

by

Abraham H. Oort

Scientific Report No, 1, 1 July 1963, 30 pages, AF19 (628)-2408 Unclassified Report.

Data of the current velocity, temperature and salinity of the Gulf Stream, collected during 200 crossings of the current in cruises off Onslow Bay, Jacksonville $\left(30^{\circ} \mathrm{N}\right)$ and Cape Hatteras, are used to compute the eddy fluxes of heat and density across the mean current. In each cruise an eddy transport of heat is observed, which is directed from the colder coastal water to the Sargasso Sea in the surface layers. The meanders in the stream appear to increase the thermal contrast across the so called Gulf Stream front and thus violate the ordinary diffusion laws by not transporting heat from the warm to the cold source. The transport of density across the stream is, in general, towards the shore, reflecting mostly the influence of the temperature on the density. Since the meanders of the scale considered in this study appear to speed up the Gulf Stream and do not feed upon, but actually build up the thermal contrast near the surface, these eddies must be forced.
Unclassified

1. Gulf Stream

2. Heat and density transport

3. Abraham H. Oort 

Planetary Circulations Project, Massachusetts Institute of Technology Cambridge, Massachusetts

Report No. AFCRL - 63

\section{COMPUTATIONS OF THE EDDY HEAT AND DENSITY TRANSPORTS ACROSS THE GULF STREAM}

by

Abraham H. Oort

Scientific Report No, 1, 1 July 1963, 30 pages, AF19 (628)-2408 Unclassified Report.

Data of the current velocity, temperature and salinity of the Gulf Stream, collected during 200 crossings of the current in cruises off Onslow Bay, Jacksonville $\left(30^{\circ} \mathrm{N}\right)$ and Cape Hatteras, are used to compute the eddy fluxes of heat and density across the mean current. In each cruise an eddy transport of heat is observed, which is directed from the colder coastal water to the Sargasso Sea in the surface layers. The meanders in the stream appear to increase the thermal contrast across the so called Gulf Stream front and thus violate the ordinary diffusion laws by not transporting heat from the warm to the cold source. The transport of density across the stream is, in general, towards the shore, reflecting mostly the influence of the temperature on the density. Since the meanders of the scale considered in this study appear to speed up the Gulf Stream and do not feed upon, but actually build up the thermal contrast near the surface, these eddies must be forced.
Unclassified

1. Gulf Stream

2. Heat and density transport

3. Abraham H. Oort
Planetary Circulations Project, Massachusetts Institute of Technology Cambridge, Massachusetts

Report No. AFCRL - 63

\section{COMPUTATIONS OF THE EDDY HEAT AND DENSITY TRANSPORTS ACROSS THE GULF STREAM \\ by \\ Abraham H. Oort}

Scientific Report No. 1, 1 July 1963, 30 pages, AF19 (628)-2408 Unclassified Report.

Data of the current velocity, temperature and salinity of the Gulf Stream, collected during 200 crossings of the current in cruises off Onslow Bay, Jacksonville $\left(30^{\circ} \mathrm{N}\right)$ and Cape Hatteras, are used to compute the eddy fluxes of heat and density across the mean current. In each cruise an eddy transport of heat is observed, which is directed from the colder coastal water to the Sargasso Sea in the surface layers. The meanders in the stream appear to increase the thermal contrast across the so called Gulf Stream front and thus violate the ordinary diffusion laws by not transporting heat from the warm to the cold source. The transport of density across the stream is, in general, towards the shore, reflecting mostly the influence of the temperature on the density. Since the meanders of the scale considered in this study appear to speed up the Gulf Stream and do not feed upon, but actually build up the thermal contrast near the surface, these eddies must be forced.
Unclassified

1. Gulf Stream

2. Heat and density transport

3. Abraham H. Oort 




\section{(1)}

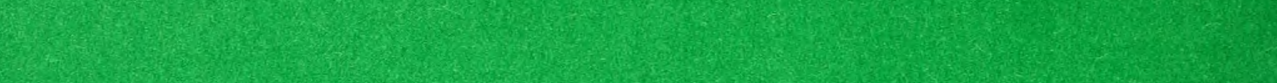

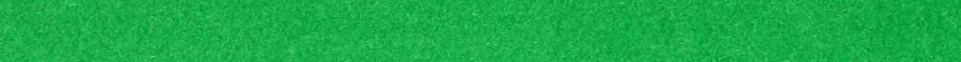
2.

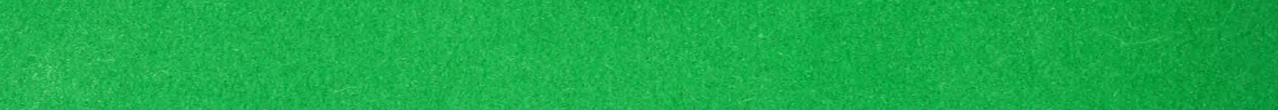

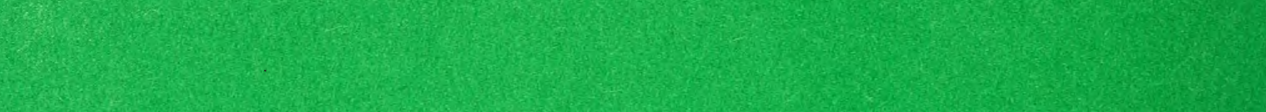

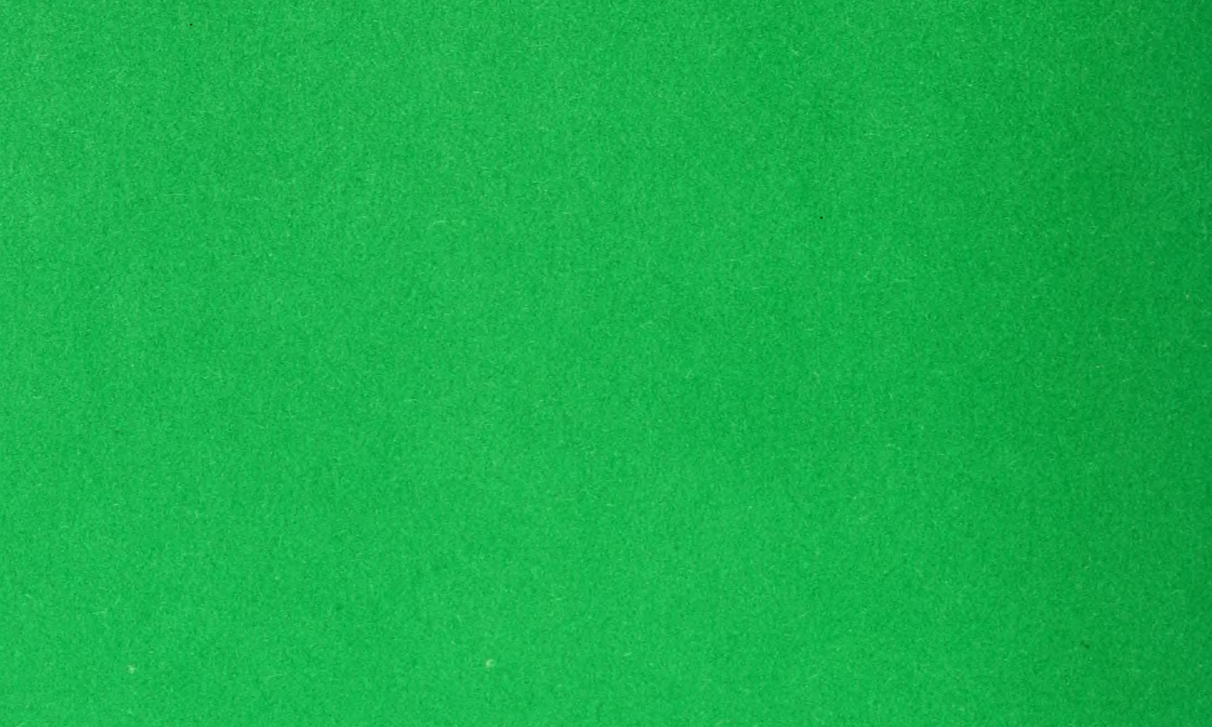

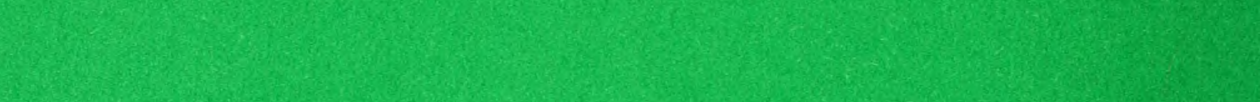

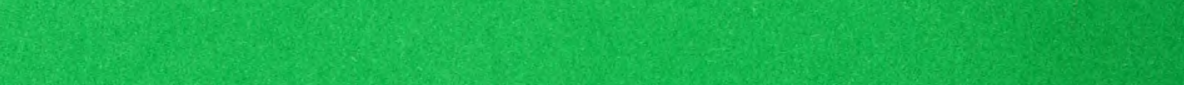
2. (x)

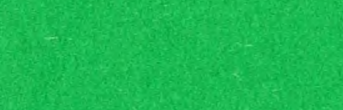

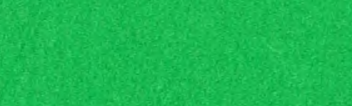
20

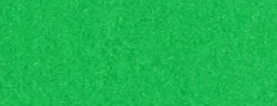

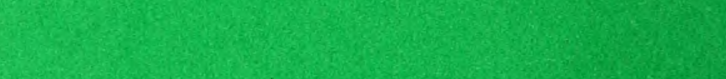
4.

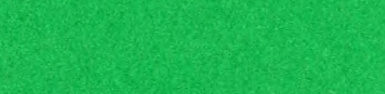

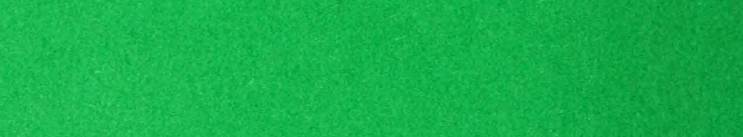

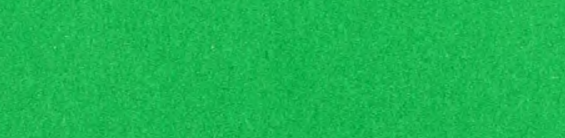
(1)

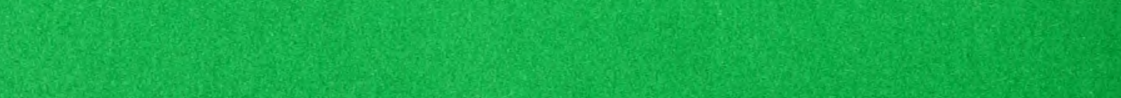

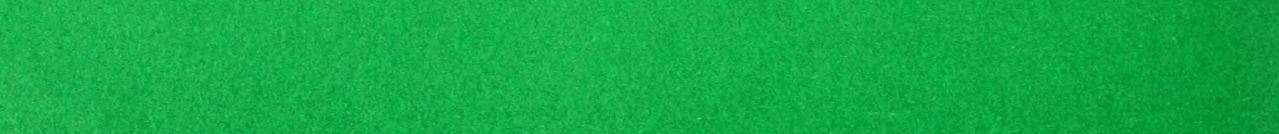

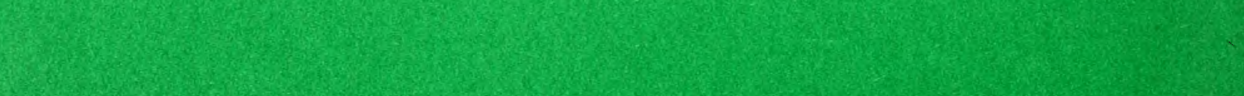

